\title{
Urgent laparoscopic gastrocystostomy after iatrogenic perforation of pancreatic cyst - case report and literature review
}

\author{
Andrzej P. Kwiatkowski, Piotr K. Kowalewski, Krzysztof Paśnik \\ Department of General, Oncological, Metabolic and Thoracic Surgery, Military Institute of Medicine, Warsaw, Poland
}

Videosurgery Miniinv 2015; 10 (2): 328-331

DOI: $10.5114 /$ wiitm.2015.49248

\begin{abstract}
Pancreatic cysts, a common complication of pancreatitis, often require invasive treatment. When possible, endoscopic technique tends to be the procedure of choice. Despite its advantages, most of its complications may require immediate surgical assistance. Experienced surgeons tend to choose a laparoscopic approach bearing in mind its advantages. We present a case of a 71 -year-old patient with an idiopathic pancreatic cyst, causing chronic epigastric pain. The attempt of endoscopic drainage led to iatrogenic perforation, which was successfully managed by laparoscopic posterior gastrocystostomy. The postoperative course was uneventful. In our opinion, laparoscopy should always be considered to manage complications caused by endoscopic drainage of a pancreatic pseudocyst.
\end{abstract}

Key words: laparoscopy, pancreatitis, pancreatic pseudocyst, posterior gastrocystostomy.

\section{Introduction}

Pancreatic fluid collections, especially pseudocysts, constitute one of the most common complications of acute and chronic pancreatitis or pancreatic blunt injury. Most of the cysts, especially symptomatic, infected or enlarging, require invasive treatment. Out of the common drainage methods, the endoscopic technique tends to be the procedure of choice. Despite its many advantages, it also presents a significant complication rate, including perforation, reported in up to $18 \%$ of all cases [1]. latrogenic gastric or intestinal wall defect requires urgent surgical assistance. The development of laparoscopic techniques, performed by experienced surgeons, favors minimally invasive procedures in comparison to open surgery. Several laparoscopic techniques are described for pseudocyst drainage, among which the anterior, transluminal, and posterior cystogastrostomies are the most frequently mentioned in the literature [1, 2].

\section{Case report}

A 71-year-old female patient with a medical history of type 2 diabetes, hypertension, left bundle branch block (LBBB), laparoscopic cholecystectomy and thyroidectomy was admitted to the Department of Gastroenterology with chronic abdominal pain and a pathological mass situated between the pancreas, spleen and left kidney, confirmed in a sonogram. Abdominal computed tomography (CT) scan revealed a large peripancreatic fluid collection (125 $\times$ $65 \times 70 \mathrm{~mm}$ ) with a defined capsule, located next to the body and tail of the pancreas, presenting the morphological image of a pseudocyst (Photo $1 \mathrm{~A}$ ). After endosonography (EUS) and retrograde cholangiopancreatography (ERCP), endoscopic drainage was chosen as the most suitable treatment. During the procedure the endoscopist was unable to penetrate the cyst's capsule; therefore subsequent attempts were not made. Immediately after the procedure the patient reported acute epigastric pain

\section{Address for correspondence}

Piotr K. Kowalewski MD, Department of General, Oncological, Metabolic and Thoracic Surgery, Military Institute of Medicine, 128 Szaserow St, 04-141 Warsaw, Poland, phone: +48 504445 800, e-mail: pietia.kowalewski@gmail.com 

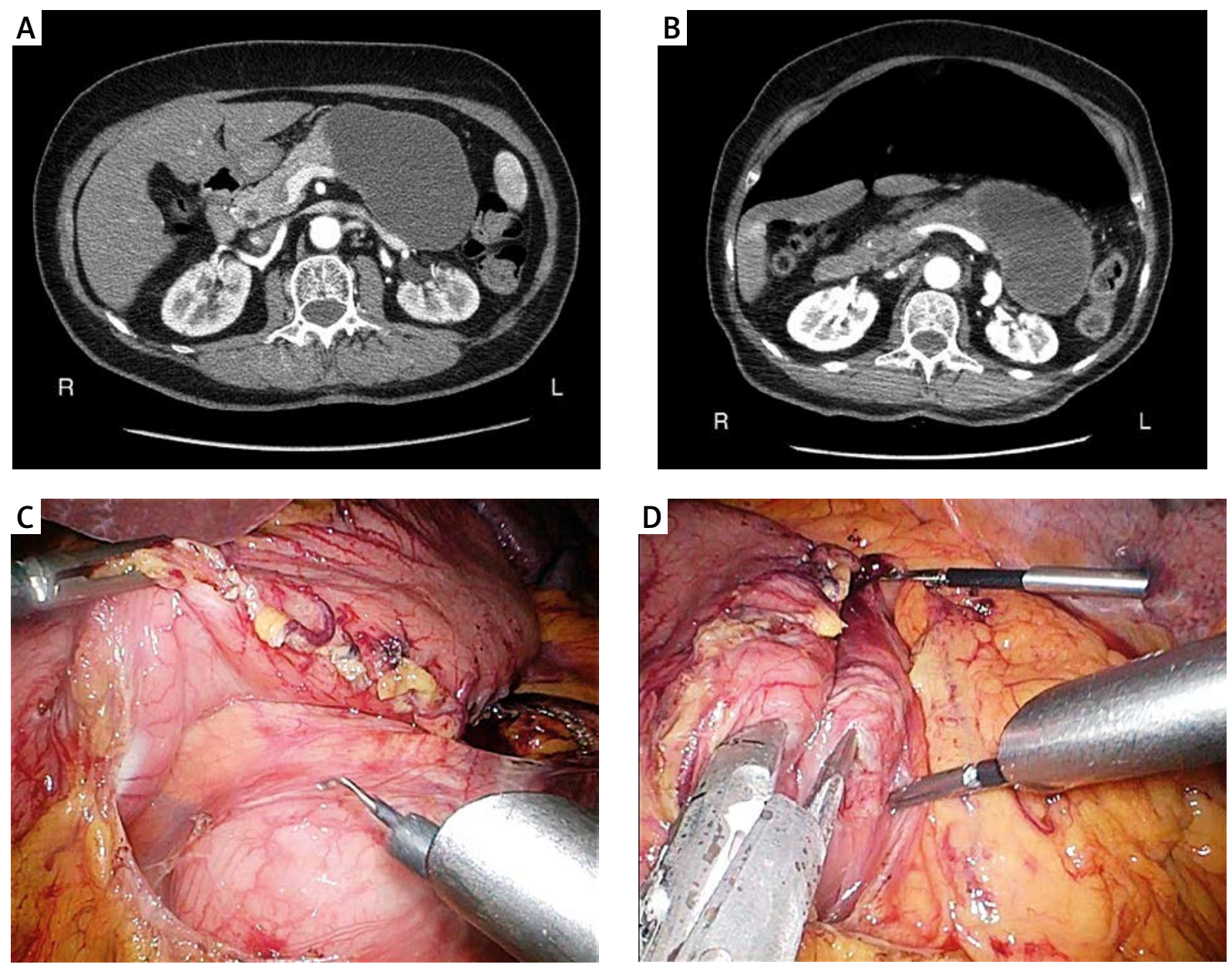

Photo 1 A-D. Computed tomography radiologial images and intraoperative view

and bloating. Immediate CT scan revealed pneumoperitoneum (Photo 1 B) - an obvious manifestation of gastric perforation. After necessary preparation the patient was qualified for urgent exploratory laparoscopy. Five trocars were used: one $12 \mathrm{~mm}$, three $10 \mathrm{~mm}$ and one $5 \mathrm{~mm}$ (Figure 1). The peritoneal cavity was inspected. The omental bursa was opened through the gastrocolic ligament, along the stomach's greater curvature, with ultrasonic scissors (SonoSurg, Olympus) (Photo 1 C). A small amount of clear fluid and the perforation site on the posterior wall, next to the lesser curvature, were revealed. The gap was immediately sealed with double-layer interrupted manual suture. Next, the pancreatic body cyst was exposed, punctured and drained for microbiological culture and amylase count. Afterwards, a gastrocystostomy with the posterior wall was performed using a $60 \mathrm{~mm}$ EndoGIA stapler (purple cartridge, Covidien) (Photo 1 D). The remaining opening was sealed with a single-layer continuous manual suture. The gastrocystostomy was then checked for leakage with dye introduced to the stomach - no sign of extravasation was found. The abdomen was copiously irrigated with saline, and two surgical drains were placed: one in the omental bursa, the other one in the rectouterine pouch. The estimated blood loss was minimal. The procedure lasted $95 \mathrm{~min}$. The patient made an uneventful postoperative recovery, with oral nutrition introduced successfully on day 4 , and was discharged on day 6 .

Follow-up ultrasound performed 3 months after the surgery presented a residual area in the lesser $\mathrm{sac}$, approx. $57 \times 39 \mathrm{~mm}$, without any fluid or pathological mass present.

\section{Discussion}

Pancreatic fluid collections are divided into 4 groups according to the Atlanta classification system for 


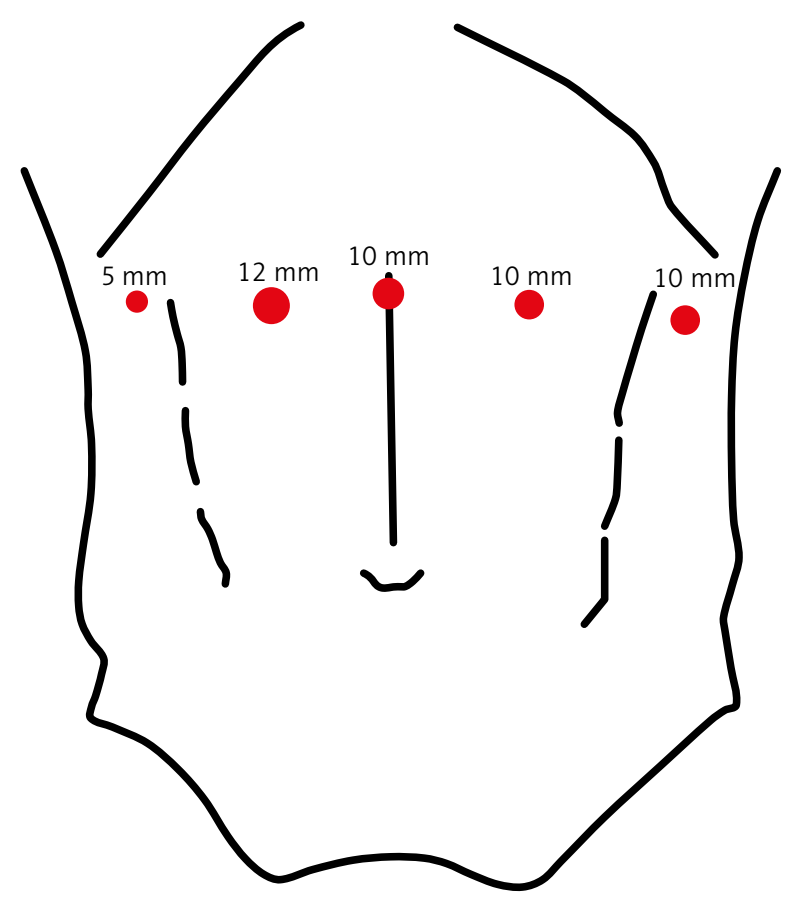

Figure 1. Placement of trocars

acute pancreatitis: acute peripancreatic fluid collections, acute pseudocysts, chronic pseudocysts and pancreatic abscesses (Table I). They occur in about $5 \%$ of cases of acute and $20-40 \%$ of cases of chronic pancreatitis [3]. Fluid collections not related to pancreatitis should always arouse the suspicion of a neoplastic cyst. The most common diagnostic tool is abdominal ultrasound, followed by a CT scan or magnetic resonance imaging (MRI). Endoscopic sonography has the advantage of performing a fine-needle aspiration along with precise imaging of the lesion. Available treatment options include watchful waiting ( $65 \%$ of acute pseudocysts resolve spontaneously) or an intervention (drainage). The ba- sic indications for pseudocyst drainage are fairly simple: all of the pseudocysts that are symptomatic (mostly painful), enlarging, infected, or those that affect contiguous organs, should be drained. There are three basic methods of drainage: percutaneous, endoscopic and surgical. The endoscopic approach, preceded by ERCP, whether transpapillar or EUS-guided, is considered to be the method of choice $[4,5]$. Still, complications occur in $30 \%$ of procedures, among which severe bleeding (5\%) and perforation (18\%) require immediate surgical attention [6,7]. While considering the appropriate surgical technique, the laparoscopic approach carries certain benefits typical for minimally invasive surgery - shorter mean hospital stay, lower morbidity, and quicker patient's recuperation [1, 8, 9]. As regards cystogastrostomy, Fernández-Cruz et al. mention three laparoscopic techniques: the intramural cystogastrostomy, with radially expending trocars inserted into the stomach; the anterior gastrostomy, facilitating access to the posterior wall of the stomach; and the posterior cystogastrostomy, through the lesser sac [1]. Only the last technique does not require access to the stomach's lumen, yet it presents various technical difficulties, therefore requiring advanced laparoscopic skills from the surgeon. Although there are several guidelines to minimally invasive management of pancreatic pseudocysts, only a few papers compare laparoscopic techniques. Those that do favor the posterior approach for its precision, better cyst visualization, easier tissue sample collection and wider anastomosis between the lesion and stomach $[10,11]$. In case of urgent surgery provoked by complications during endoscopy Elmunzer et al. doubt the necessity of exposure of the lesser $\mathrm{sac}$ and management of the fluid - yet the approach presented by those authors involved the perforation

Table I. Peripancreatic fluid collections [3]

\begin{tabular}{|ll|}
\hline Type of fluid collection & Definition \\
\hline Acute fluid collections & $\begin{array}{l}\text { Occur early in the course of acute pancreatitis, are located in or near the pancreas, and always lack } \\
\text { a wall of granulation or fibrous tissue }\end{array}$ \\
\hline Acute pseudocysts & $\begin{array}{l}\text { Constituted by pancreatic juice enclosed by a wall of fibrous or granulation tissue, arising as a con- } \\
\text { sequence of acute pancreatitis or pancreatic trauma }\end{array}$ \\
\hline Chronic pseudocysts & $\begin{array}{l}\text { Constituted by pancreatic juice enclosed by a wall of fibrous or granulation tissue, arising as a con- } \\
\text { sequence of chronic pancreatitis and lacking an antecedent episode of acute pancreatitis }\end{array}$ \\
\hline Pancreatic abscess & $\begin{array}{l}\text { A circumscribed intra-abdominal collection of pus, usually in proximity to the pancreas, containing } \\
\text { little or no pancreatic necrosis, arising as the consequence of acute pancreatitis, trauma or chronic } \\
\text { pancreatitis }\end{array}$ \\
\hline
\end{tabular}


of an already debrided cyst, less likely to produce peritonitis. Moreover, the perforation of the gastric wall in their case was sealed through a sophisticated endoscopic maneuver involving six clips and two endoloops, which must have required the assistance of a well-trained endoscopist [12].

\section{Conclusions}

Laparoscopy, thanks to its advantages, should always be considered when managing complications of pancreatic pseudocyst endoscopic drainage. In our opinion, the posterior approach, achieved by opening the lesser sac through the gastrocolic ligament, gives better exposure, allowing easier sealing of the gastric wall defect and broader anastomosis.

\section{Conflict of interest}

The authors declare no conflict of interest.

\section{References}

1. Fernández-Cruz L, Sáenz A, Astudillo E, et al. Laparoscopic prancreatic surgery in patients with chronic pancreatitis. Surg Endosc 2002; 16: 996-1003.

2. Šileikis $A$, Beiša $A$, Zdanytèc $E$, et al. Minimally invasive management of pancreatic pseudocysts. Videosurgery Miniinv 2013; 8: 211-5.

3. Andrén-Sandberg A, Dervenis C. Pancreatic pseudocysts in the 21st century. Part I: classification, pathophysiology, anatomic considerations and treatment. JOP. J Pancreas (Online) 2004; 5: 8-24.

4. Byrne MF, Mitchell RM, Baillie J. Pancreatic pseudocysts. Curr Treat Options Gastroenterol 2002; 5: 331-8.

5. Krasowski G, Budzynski A, Miodoński A, et al. Laparoscopic splenectomy complicated by pancreatic cyst in the course of Hodgkin's disease: case report. Videosurgery Miniinv 2013; 8: 352-6.

6. Rosso E, Alexakis N, Ghaneh P, et al. Pancreatic pseudocyst in chronic pancreatitis: endoscopic and surgical treatment. Dig Surg 2003; 20: 397-406.

7. Beckingham IJ, Krige JE, Bornman PC, et al. Endoscopic management of pancreatic pseudocysts. Br J Surg 1997; 84: 1638-45.

8. Costi R, Randone B, Mal F, et al. Laparoscopic minor pancreatic resections (enucleations/atypical resections). A long-term appraisal of a supposed mini-invasive approach. Videosurgery Miniinv 2013; 8: 117-29.

9. Palanivelu C, Senthilkumar K, Madhankumar MV, et al. Management of pancreatic pseudocyst in the era of laparoscopic surgery: experience from a tertiary centre. Surg Endosc 2007; 21: $2262-7$

10. Oida T, Mimatsu K, Kawasaki A, et al. Long-term outcome of laparoscopic cystogastrostomy performed using a posterior approach with a stapling device. Dig Surg 2009; 26: 110-4.
11. Barragan B, Love L, Wachtel M, et al. A comparison of anterior and posterior approaches for the surgical treatment of pancreatic pseudocyst using laparoscopic cystogastrostomy. J Laparoendosc Adv Surg Tech A 2005; 15: 596-600.

12. Elmunzer BJ, Boetticher NC, Mobley CM, et al. Iatrogenic pancreatic cyst perforation successfully managed by a minimally invasive combined endoscopic-laparoscopic approach. J Laparoendosc Adv Surg Tech A 2010; 20: 717-9.

Received: 8.12.2014, accepted: 23.12.2014. 